\title{
THE COST-EFFECTIVENESS OF ANTENATAL MALARIA PREVENTION IN SUB-SAHARAN AFRICA
}

\author{
CATHERINE A. GOODMAN, PAUL G. COLEMAN, AND ANNE J. MILLS \\ Health Policy Unit, Department of Public Health and Policy, London School of Hygiene and Tropical Medicine, \\ London, United Kingdom; Disease Control and Vector Biology Unit, Department of Infectious and Tropical Diseases,
} London School of Hygiene and Tropical Medicine, London, United Kingdom

\begin{abstract}
Antimalarial chemoprophylaxis during pregnancy significantly increases the birth weight of babies born to primigravidae, but coverage in sub-Saharan Africa is very limited. This analysis assessed whether increasing coverage is justified on cost-effectiveness grounds. A standardized modeling framework was used to estimate ranges for the cost per discounted year of life lost averted by weekly chloroquine chemoprophylaxis and intermittent sulfadoxine-pyrimethamine (SP) treatment for primigravidae in an operational setting with moderate to high malaria transmission. The SP regimen was found to be more cost-effective than the chloroquine regimen, because of both lower costs and higher compliance. Both regimens appear to be a good value for money in comparison with other methods of malaria control and based on rough cost-effectiveness guidelines for low-income countries, even with high levels of drug resistance. However, extending the SP regimen to all gravidae and increasing the number of doses per pregnancy could make the intervention significantly less cost-effective.
\end{abstract}

\section{INTRODUCTION}

The Global Malaria Control Strategy of the World Health Organization (WHO) advocates that all pregnant women in malaria-endemic areas receive regular chemoprophylaxis against malaria. ${ }^{1}$ In practice, the coverage of effective antenatal malaria prevention in sub-Saharan Africa is very limited. $^{2}$ A survey of 4 African countries found that only $1-$ $18 \%$ of women reported following an antimalarial drug regimen close to the WHO recommendation. ${ }^{3}$ Common problems are that provision in government health facilities is limited, antenatal care attendance inadequate, compliance with therapy poor, and resistance to the most widely used drug widespread. This analysis assesses whether, in view of these constraints, a drive to increase coverage in endemic areas of sub-Saharan Africa is justified on cost-effectiveness grounds.

Pregnant women are particularly vulnerable to malaria. Infection may cause harmful effects for the mother, and placental parasitemia retards the growth of the fetus and increases the prevalence of low birth weight (LBW), the proportion of newborns weighing less than 2,500 g. ${ }^{4-6}$ This is of particular concern because LBW is associated with increased neonatal mortality. ${ }^{7}$ In areas of high transmission, the effects are most marked in women during their first pregnancy (primigravidae). ${ }^{8}$ Antimalarial chemoprophylaxis during pregnancy has been shown to reduce the risk of malaria infection in all pregnant women and to increase significantly the birth weight of babies born to primigravidae. ${ }^{9}$ To date, the most commonly used regimen is weekly chloroquine (CQ). Chloroquine resistance has been recorded across Africa, although levels vary considerably: in some areas, particularly in West Africa, the prevalence of treatment failure remains under $25 \%$, but rates of over $50 \%$ have been recorded in Kenya, Tanzania, Ethiopia, and Rwanda (WHO/ AFRO, unpublished data). Intermittent treatment with sulfadoxine-pyrimethamine (SP) is now considered a potential alternative and has been introduced in Malawi and approved in Kenya. ${ }^{3,10}$ Apart from lower levels of drug resistance, SP has the additional advantage that it is taken in only 2 or 3 doses and is therefore likely to have higher rates of compliance than the weekly CQ regimen.

To decide on the priority to attach to antenatal prevention, policy makers need information on cost-effectiveness and on the way cost-effectiveness changes with increasing drug resistance. Although a few studies are available, ${ }^{11-14}$ they relate to a limited number of settings and intervention specifications, and the results are not comparable with cost-effectiveness estimates for other malaria control interventions because of the partial costing methodology and/or intermediate outcome measures used. ${ }^{15}$ A standardized modeling framework was used to provide estimates of the cost-effectiveness of the CQ and SP regimens in an operational setting with moderate to high malaria transmission. The model combined data from the Cochrane meta-analysis of strategies for preventing malaria in pregnancy ${ }^{9}$ with information on costs and compliance from a range of published and unpublished sources. To facilitate comparisons with other methods of malaria control and interventions for other health problems, the full incremental costs of the interventions were included, and the benefits were expressed in terms of a generic health outcome measure. The impact on cost-effectiveness of different levels of antimalarial drug resistance and changes in the intervention specification were explored.

\section{METHODS}

Interventions. The interventions considered were the provision of CQ chemoprophylaxis or SP intermittent treatment as an addition to standard antenatal care (ANC) services, with antimalarial drugs distributed during 2 ANC visits in the second and third trimesters. The regimens considered were a weekly CQ dose of $300 \mathrm{mg}$, with tablets prescribed at ANC visits and taken home by women, and 2 doses of $\mathrm{SP}, 1,500 \mathrm{mg} / 75 \mathrm{mg}$, taken during ANC visits. Both interventions were considered initially for primigravidae only.

Modeling framework. This analysis formed part of a larger study that used a standardized analytical framework to calculate comparable cost-effectiveness estimates for a range of interventions to prevent malaria and improve its treatment in sub-Saharan Africa. ${ }^{16,17}$ Effectiveness was cal- 
culated in terms of discounted years of life lost (DYLLs) averted, the mortality component of the disability adjusted life year (DALY). ${ }^{18}$ The analysis was performed for 3 economic strata, defined on the basis of per capita gross national product (GNP): very low income (under US\$315), middle income (between US\$315 and \$1,000), and higher income (above US $\$ 1,000$ ). Discounted years of life lost averted were combined with costs to produce a likely range for the cost per DYLL averted of each intervention. To capture the uncertainty and variability surrounding many of the parameter estimates, probabilistic sensitivity analysis was used, meaning that ranges and probability distributions were attached to model input variables, and the cost-effectiveness outcome was calculated as a probability distribution, rather than a single point estimate.

Calculating effectiveness. Effectiveness estimates were based on the Cochrane meta-analysis of chemoprophylaxis, which found a significant increase in the birth weight of children born to primigravidae (but not multigravidae). ${ }^{9}$ The sample sizes of the studies in the meta-analysis were too small to demonstrate a significant impact on neonatal mortality, so in order to calculate DYLLs averted, a model of birth weight and child survival was developed to extrapolate from the increase in birth weight to a reduction in neonatal mortality, and the fall in mortality was converted to DYLLs. Unlike other analyses, which have used a birth weight cutoff of 2,500 $\mathrm{g}$ and have ascribed different neonatal mortality rates to children above and below this threshold, ${ }^{13}$ this model incorporated the continuum of birth weights and birth weight-specific mortality.

Birth weight distribution. An initial birth weight distribution for children born to primigravidae in the absence of any antimalaria intervention was constructed using empirical estimates. It was assumed that birth weights were normally distributed and, therefore, fully defined by the mean $\mu$ and standard deviation $\sigma$. It would be more accurate to describe birth weights as a combination of 2 distributions: a predominantly normal distribution, and a second residual distribution for low birth weights with a much lower mean. ${ }^{19}$ By assuming that the whole distribution is normal, the prevalence of LBW and therefore effectiveness will be slightly underestimated, making the estimates of cost-effectiveness conservative. The relative frequency $f$ of birth weight $x \mathrm{~kg}$ was calculated from the area under the normal distribution, assuming that birth weights lie in the range of 1.0 to $4.5 \mathrm{~kg}$ and grouping birth weights to the nearest $0.1 \mathrm{~kg}$. A range of estimates for $\mu$ and $\sigma$ for babies born to women who had not received chemoprophylaxis or intermittent treatment was gathered from published data on birth weights in primigravidae in malarious settings in sub-Saharan Africa. ${ }^{20-23}$

Birth weight-specific neonatal mortality. Birth weightspecific neonatal mortality $m_{x}$ was defined as the proportion of live newborns of birth weight $x \mathrm{~kg}$ who die during the neonatal period, the first $28 \mathrm{~d}$ of life. Data on continuous birth weight-specific mortality for Africa are very limited, ${ }^{24}$ and empirical observations were restricted to 2 studies, conducted in The Gambia and Malawi. ${ }^{25,26}$ A Wilcox-Russell model of mortality, ${ }^{19,27,28}$ taking the form

$$
m_{x}=k+\frac{e^{a-b x}}{1+e^{a-b x}}+\frac{e^{a^{\prime}+b x}}{1+e^{a^{\prime}+b x}}
$$

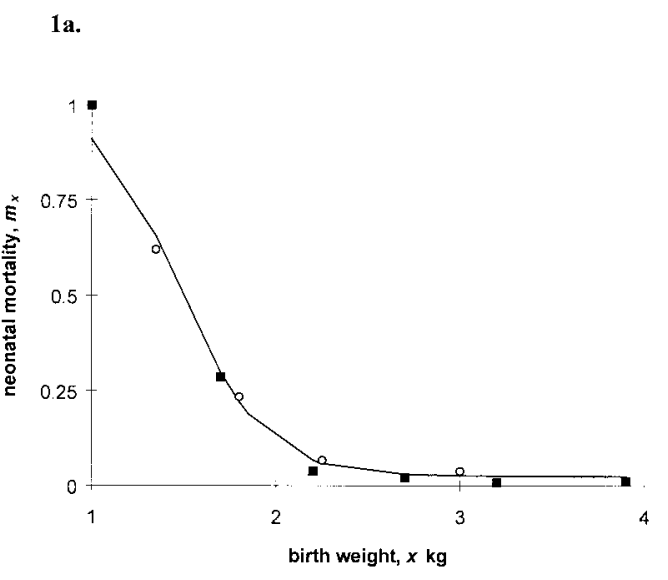

$1 b$.

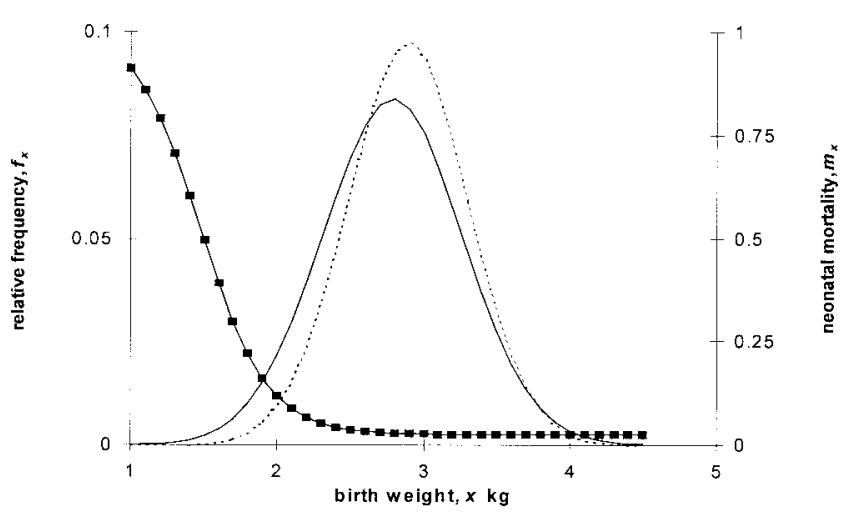

FIGURE 1a. Empirical estimates of birth weight-specific neonatal mortality $\left(m_{x}\right)$ from Malawi $(\mathbf{\square})$ and The Gambia $(O)$, and the fitted model $(\stackrel{-}{\longrightarrow}$ described by equation 1. FIGURE 1b. Illustrative example of the birth weight distributions in unprotected (-) and protected $(---)$ primigravidae and the birth weight-specific neonatal mortality curve $\left(m_{x}\right)(-\mathbf{\square}-)$.

where $k, a, a^{\prime}$, and $b$ are constants, was fitted directly to the empirical neonatal mortality observations (see Figure 1a). Empirical $m_{x}$ values were assumed to have binomial errors, and equation 1 was fitted iteratively in Microsoft Excel to maximize the likelihood between the observed and fitted values. ${ }^{29}$ The fitted estimates for the parameters in equation 1 were $k=0.0249, a=6.3749, a^{\prime}=-37.2204$, and $b=$ 4.3301 .

The crude neonatal mortality rate (NNMR) was calculated from the $f_{x}$ distribution and $m_{x}$ curve as

$$
\mathrm{NNMR}=\sum_{x=1.0}^{x=4.5} f_{x} m_{x} .
$$

Effect of antimalarial drugs. Antenatal chemoprophylaxis or intermittent treatment was considered to lead to a shift in the birth weight frequency distribution, increasing $\mu$ by $i \mathrm{~kg}$ relative to no protection. The proportion of high birth weights (greater than $3.5 \mathrm{~kg}$ ) was assumed to be the same with or without the intervention. ${ }^{22,30}$ It follows that if $\mu_{u}$ and $\sigma_{u}$ describe the birth weight distribution in women who did not receive the intervention (referred to as "unprotected") 
and $\mu_{p}$ and $\sigma_{p}$ the distribution in those who did (referred to as "protected"), then

$$
\frac{3.5-\mu_{u}}{\sigma_{u}}=\frac{3.5-\mu_{p}}{\sigma_{p}} .
$$

The average magnitude of $i$ was reported in the Cochrane meta-analysis. ${ }^{9}$ In studies including all pregnant women, the overall impact on birth weight was not significant, but for primigravidae alone, the mean birth weight in the protected group was significantly greater than in the unprotected group (difference of $0.101 \mathrm{~kg}$, with a standard deviation of 0.042 $\mathrm{kg}$ ). It was assumed that the efficacy data from the metaanalysis were based on study cohorts with close to full compliance, in the absence of drug resistance, and therefore represent the maximum effectiveness that could be achieved. Although none of the studies included in the meta-analysis used the SP regimen, it was assumed that the same effect on birth weight would be obtained, as this regimen is highly effective in decreasing the prevalence of both placental parasitemia and severe maternal anemia. ${ }^{31,32}$

For a given value of $i$, the difference $d$ between NNMRs in protected and unprotected primigravidae was calculated from the birth weight distributions and the $m_{x}$ schedule (see Figure 1b). The NNMR difference $d$ is the maximum level of effectiveness achieved in a situation of complete parasite sensitivity to the drugs, where all pregnant woman complied fully with the correct regimen and there were no stillbirths. This will not occur in practice for several reasons: resistance to CQ is already high in many areas of Africa, and resistance to SP is starting to grow; attendance at antenatal services is often intermittent; and compliance with drug therapy has been shown to be very low. ${ }^{12,33,34}$ It was therefore necessary to estimate the effective NNMR difference $D$, which adjusts $d$ by taking into account the level of drug resistance $r$; the probabilities of attending the antenatal clinic in the first or second trimester, $v_{1}$, returning for a second clinic visit, $v_{2}$, and compliance with the correct drug regimen, $g$; and the stillbirth rate $s$, as it was assumed that neither intervention affects the primigravidae stillbirth rate. ${ }^{20}$ It was assumed that the regimens were only effective if women made their first visit before the end of the second trimester and made at least 2 visits per pregnancy. These are conservative assumptions, as it is possible that there would be some beneficial effects if chemoprophylaxis or intermittent treatment were started later in the pregnancy or if fewer doses were received. ${ }^{32}$

Full compliance implies that the drugs were procured, the correct dose taken, and the doses taken at the correct time. Patient compliance $g$ was considered to equal 1 minus the probability of underdosing, with the effects of overdosing and incorrect timings ignored, although overdosing could potentially lead to toxic side effects. Estimates for underdosing with CQ prescribed during ANC were taken from 2 studies in Malawi. ${ }^{11,12}$ No data were available for compliance with SP. It was assumed that because it is taken in a series of single doses rather than on a weekly basis, compliance would be much higher than with CQ, though not necessarily $100 \%$, because, for example, patients may be anxious about side effects. Compliance with SP was therefore set at between $85 \%$ and $95 \%$ for each dose. In some cases of noncompliance with $\mathrm{CQ}$, only minor underdosing may occur; its impact on effectiveness is not known, but it is very unlikely that all those who underdose receive zero effects. In the absence of drug resistance, it was assumed that underdosing with the 2-dose SP regimen led to zero effectiveness, but the proportion of underdosed CQ cases where the drug was still effective $(z)$ was set between 0.1 and 0.3 .

The effective reduction in the NNMR $D$ was calculated as

$$
\begin{aligned}
D= & d \times(1-s) \times(1-r) \times(g+[1-g] z) \times v_{1} \\
& \times v_{2} .
\end{aligned}
$$

The parameter values for $s, v_{1}, v_{2}, z$, and $g$ were estimated from the published literature and from consultation with researchers and practitioners. $D$ was calculated as a function of resistance $r$, which was allowed to vary between 0 (complete sensitivity) and 1 (complete resistance). Resistance $r$ was defined as RII/RIII resistance (no clearance of parasitemia within $7 \mathrm{~d}$ of drug administration). It was assumed that parasitological cure was required to increase birth weight. ${ }^{3}$

The possibility of side effects from the drug regimens was not included, but they are not expected to be important. Chloroquine is known to be safe in pregnancy. Fatal side effects have been observed with SP at a rate of between 1: 11,000 and 1:25,000 when used as weekly prophylaxis, ${ }^{35}$ but side effects are likely to be much less frequent with intermittent treatment. Studies of SP use in pregnancy have not found increased risk of spontaneous abortion, congenital defects, jaundice, or kernicterus among neonates. ${ }^{32,36,37}$

Translating mortality reduction to DYLLs averted. The effective reduction in the NNMR, $D$, was converted to years of life lost (YLLs) averted per primigravida. Years of life lost were calculated using age-specific life expectancies calculated from a West African life table with a life expectancy at birth of $50 \mathrm{yr}$ for very-low-income and middle-income countries and from a General Pattern life table with a life expectancy at birth of $65 \mathrm{yr}$ for higher-income countries. ${ }^{38}$ Years of life lost were discounted at $3 \%$, and no age weighting was applied. All effectiveness input parameters are listed in Table 1.

Costs. Costs were calculated using the ingredients approach, ${ }^{39}$ with data obtained through reviews of published and unpublished literature, program budgets, price catalogs, and consultation with researchers and program managers. The incremental cost per woman was based on adding the service to an existing ANC program and included the cost of staff training, the production of health education materials, the drugs, and incremental staff time.

All cost input variables are listed in Table 2. Implementing the intervention would require additional time from ANC and supervisory staff. The cost of this time was included, because staff could be undertaking other useful activities if they were not involved in this intervention (i.e., their time has an opportunity cost). It was estimated that the intervention would add $10 \mathrm{~min}$ to the first visit and $5 \mathrm{~min}$ to the second visit, and that an additional $15 \mathrm{~min}$ of supervisory time would be required per month. Estimates of costs of fulltime equivalent staff for Safe Motherhood interventions ${ }^{40}$ were extrapolated to provide salary estimates for the 3 economic strata.

A single price was used for other inputs, because they are 
TABLE 1

Effectiveness input variables*

\begin{tabular}{|c|c|c|c|}
\hline Input variable & $\begin{array}{l}\text { Probability } \\
\text { distribution }\end{array}$ & Distribution parameters & Source \\
\hline $\begin{array}{l}\text { Mean birth weight in unprotected primigravidae, } \\
\mu_{u}(\mathrm{~kg})\end{array}$ & $\begin{array}{l}\text { Truncated nor- } \\
\text { mal }\end{array}$ & $\begin{array}{l}\text { Mean }=2.788 \\
\text { Standard deviation }=0.082 \\
\operatorname{Min}=2.690 \\
\operatorname{Max}=2.875\end{array}$ & $\begin{array}{l}\text { Greenwood and others, } 1989 ;{ }^{20} \mathrm{Me}- \\
\text { nendez and others, } 1994 ;{ }^{21} \text { Cot } \\
\text { and others, } 1995 ; 22 \text { Fleming and } \\
\text { others, } 1986^{23}\end{array}$ \\
\hline Standard deviation of birth weight, $\sigma_{\mathrm{u}}(\mathrm{kg})$ & $\begin{array}{l}\text { Truncated nor- } \\
\text { mal }\end{array}$ & $\begin{array}{l}\text { Mean }=0.476 \\
\text { Standard deviation }=0.098 \\
\text { Min }=0.36 \\
\operatorname{Max}=0.57\end{array}$ & $\begin{array}{l}\text { Greenwood and others, } 1989 ;{ }^{20} \mathrm{Me}- \\
\text { nendez and others, } 1994 ;{ }^{21} \mathrm{Cot} \\
\text { and others, } 1995 ;{ }^{22} \text { Fleming and } \\
\text { others, } 1986^{23}\end{array}$ \\
\hline Increase in birth weight, $i(\mathrm{~kg})$ & $\begin{array}{l}\text { Truncated nor- } \\
\text { mal }\end{array}$ & $\begin{array}{l}\text { Mean }=0.101 \\
\text { Standard deviation }=0.042 \\
\text { Min }=0.003 \\
\operatorname{Max}=0.198\end{array}$ & Gülmezoglu and Garner, $1998^{9}$ \\
\hline Stillbirth rate in primigravidae, $s$ & Uniform & $\begin{array}{l}\operatorname{Min}=0.062 \\
\operatorname{Max}=0.116\end{array}$ & Greenwood and others, $1994^{30}$ \\
\hline $\begin{array}{l}\text { Probability of initial clinic visit in first or second } \\
\text { trimester, } v_{1}\end{array}$ & Triangular & $\begin{array}{l}\operatorname{Min}=0.540 \\
\operatorname{Max}=0.936 \\
\mathrm{BE}=0.868\end{array}$ & Stewart and others, $1997^{34}$ \\
\hline Probability of returning for second clinic visit, $v_{2}$ & Triangular & $\begin{array}{l}\operatorname{Min}=0.835 \\
\operatorname{Max}=0.989 \\
\mathrm{BE}=0.937\end{array}$ & Stewart and others, $1997^{34}$ \\
\hline $\begin{array}{l}\text { Probability of returning for third clinic visit, } v_{3} \\
\text { (relevant where HIV prevalence is high) }\end{array}$ & Triangular & $\begin{array}{l}\operatorname{Min}=0.481 \\
\operatorname{Max}=0.942 \\
\mathrm{BE}=0.796\end{array}$ & Stewart and others, $1997^{34}$ \\
\hline \multicolumn{4}{|l|}{ Probability of compliance to prescribed drug, $g$} \\
\hline Chloroquine (average for whole course) & Uniform & $\begin{array}{l}\operatorname{Min}=0.25 \\
\operatorname{Max}=0.57\end{array}$ & $\begin{array}{l}\text { Heymann and others, } 1990 ; ;^{11} \mathrm{Hel}- \\
\text { itzer-Allen and others, } 1993^{12}\end{array}$ \\
\hline SP (per dose) & Uniform & $\begin{array}{l}\operatorname{Min}=0.85 \\
\operatorname{Max}=0.95\end{array}$ & \\
\hline SP (for 2 doses) & Uniform & $\begin{array}{l}\operatorname{Min}=0.72 \\
\operatorname{Max}=0.90\end{array}$ & \\
\hline $\mathrm{SP}$ (for 3 doses) & Uniform & $\begin{array}{l}\operatorname{Min}=0.61 \\
\operatorname{Max}=0.86\end{array}$ & \\
\hline $\begin{array}{l}\text { Proportion of underdosed cases that are effective, } \\
\quad z\end{array}$ & Triangular & $\begin{array}{l}\operatorname{Min}=0.1 \\
\operatorname{Max}=0.3\end{array}$ & \\
\hline
\end{tabular}

traded internationally. A full course of SP consists of 2 doses of $1,500 \mathrm{mg} / 75 \mathrm{mg}$, and a full course of CQ consists of 16 doses of $300 \mathrm{mg}$, based on an average first recruitment time of $22 \mathrm{wk}^{34}$ and an average gestational age at delivery of 38 wk. Transport, insurance, and delivery were assumed to add an additional $25 \%$ to the drug price, and $25 \%$ of drugs were assumed to be wasted.

Annualized costs were also included for health education materials and training, which were annualized using a discount rate of $3 \%$, and all costs were converted to 1995 US\$, using the US\$ period average market exchange rate in the study year and the U.S. Consumer Price Index. ${ }^{41,42}$ Patient travel and time costs were not included, as they were assumed to be incurred whether or not the additional antimalarial service was provided. The cost of treating drug-related side effects was not included.

The incremental cost varies with $v_{2}$ (probability of returning for second clinic visit), as the drug and staff costs of the additional visit would not be incurred if the woman failed to return. It was assumed that costs were independent of compliance, as the drug cost would be incurred whether or not the tablets were taken as prescribed, and independent of $v_{1}$ (attendance before the end of the second trimester), as drugs would be prescribed even when the first visit took place during the third trimester (although it was assumed that this would result in zero effectiveness).

Cost-effectiveness. The incremental cost-effectiveness ratio (CER) was calculated as the cost per primigravida divided by the number of DYLLs averted per primigravida. The CER outcomes were calculated as a function of parasitological resistance $r$ between 0 and 0.99 .

Sensitivity analysis. Sensitivity analysis was conducted on the values assigned to model input values and the intervention specifications.

Input variables. To allow for the high degree of uncertainty and variability surrounding many of the parameters, probability distributions based on available empirical data were assigned to the cost and effectiveness model inputs. Truncated normal distributions were assigned to $\mu_{u}, \sigma_{u}$, and $i$. For other variables, if only range information was known, a uniform distribution was assigned; if available data showed a peaked distribution, a triangular distribution was used. For each intervention scenario, the models were iterated using Monte Carlo simulations with Palisade @ RISK software, ${ }^{43}$ and the CER was expressed as a probability distribution. ${ }^{44}$ The Monte Carlo simulation was halted when all output var- 
TABLE 2

Cost input variables (all costs in 1995 US\$)

\begin{tabular}{|c|c|c|c|c|c|}
\hline & \multirow[b]{2}{*}{$\begin{array}{l}\text { Probability } \\
\text { distribution }\end{array}$} & \multicolumn{3}{|c|}{ Distribution parameters } & \multirow[b]{2}{*}{ Source } \\
\hline & & Minimum & Maximum & $\begin{array}{c}\text { Best } \\
\text { estimate }\end{array}$ & \\
\hline \multicolumn{6}{|l|}{ Drug Cost } \\
\hline \multicolumn{6}{|l|}{ Chloroquine } \\
\hline Cost of $150-\mathrm{mg}$ tablet (US\$) & Triangular & 0.008 & 0.013 & 0.01 & $\begin{array}{l}\text { Management Sciences for Health, Inter- } \\
\text { national Drug Price Indicator Guide, } \\
1996^{62}\end{array}$ \\
\hline Tablets per dose & & & & 2 & $\begin{array}{l}\text { WHO, Model Prescribing Information: } \\
\text { Drugs Used in Parasitic Diseases, } \\
1995^{63}\end{array}$ \\
\hline Doses per pregnancy & & & & 16 & \\
\hline \multicolumn{6}{|l|}{ Sulfadoxine-pyrimethamine } \\
\hline Cost of $500 \mathrm{mg} / 25 \mathrm{mg}$ tablet (US\$) & Triangular & 0.032 & 0.040 & 0.036 & $\begin{array}{l}\text { Management Sciences for Health, Inter- } \\
\text { national Drug Price Indicator Guide, } \\
1996^{62}\end{array}$ \\
\hline Tablets per dose & & & & 3 & $\begin{array}{l}\text { WHO, Model Prescribing Information: } \\
\text { Drugs Used in Parasitic Diseases, } \\
1995^{63}\end{array}$ \\
\hline Doses per pregnancy & & & & 2 & \\
\hline $\begin{array}{l}\text { Delivery cost as percentage of warehouse } \\
\text { cost }\end{array}$ & & & & $25 \%$ & Foster, $1991^{64}$ \\
\hline Wastage of drugs & & & & $25 \%$ & \\
\hline \multicolumn{6}{|l|}{ Salaries per annum (US\$) } \\
\hline \multicolumn{6}{|l|}{ Health center staff } \\
\hline Very-low-income countries & Uniform & 1,934 & 2,617 & & Extrapolation from Tinker \& Koblinsky \\
\hline Middle-income countries & Uniform & 2,544 & 3,442 & & $1992,{ }^{40}$ plus and minus $15 \%$ \\
\hline Higher-income countries & Uniform & 7,312 & 9,893 & & \\
\hline \multicolumn{6}{|l|}{ Supervisory staff } \\
\hline Very-low-income countries & Uniform & 3,137 & 4,244 & & Extrapolation from Tinker \& Koblinsky \\
\hline Middle-income countries & Uniform & 4,127 & 5,584 & & $1992,{ }^{40}$ plus and minus $15 \%$ \\
\hline Higher-income countries & Uniform & 11,868 & 16,057 & & \\
\hline Days worked per year & & & & 236 & \\
\hline Hours worked per day & & & & 8 & \\
\hline \multicolumn{6}{|l|}{ Health center incremental staff time } \\
\hline Per initial visit (min) & & & & 10 & \\
\hline Per subsequent visit (min) & & & & 5 & \\
\hline $\begin{array}{l}\text { Supervisory incremental staff time per } \\
\text { health center per month (min) }\end{array}$ & & & & 15 & \\
\hline \multicolumn{6}{|l|}{ Health Education } \\
\hline Cost per flipchart (US\$) & Uniform & 10.95 & 14.81 & & Helitzer-Allen and others, $1993^{12}$ \\
\hline Cost per book/poster (US\$) & Uniform & 4.11 & 5.55 & & \\
\hline Number of flipcharts per clinic & & & & 1 & \\
\hline Number of books/posters per clinic & & & & 5 & \\
\hline Useful life of health education materials (yr) & & & & 4 & \\
\hline \multicolumn{6}{|l|}{ Training } \\
\hline Cost of training per person (US\$) & & & & 10 & \\
\hline Number of staff trained per clinic & & & & 2 & \\
\hline Useful life of training (yr) & & & & 2 & Picard and others, $1993^{65}$ \\
\hline \multicolumn{6}{|l|}{ Utilization data } \\
\hline Number of antenatal visits per clinic per year & Uniform & 209 & 1,056 & & $\begin{array}{l}\text { Ogunbekun and others, 1996; }{ }^{66} \text { Hanson } \\
\text { and Chindele, 1992;67 Hanson and } \\
\text { Nkunzimana, } 1992^{68}\end{array}$ \\
\hline $\begin{array}{l}\text { Primigravidae as a proportion of antenatal at- } \\
\text { tendees }\end{array}$ & & & & 0.25 & $\begin{array}{l}\text { Approximation based on data from } \\
\text { Stewart and others, } 1997 ;{ }^{34} \text { World } \\
\text { Bank } 1997 ;{ }^{47} \text { Steketee and others, } \\
\text { 1996;69 Mnyika and others, } 1995^{70}\end{array}$ \\
\hline Number of visits per pregnancy & Triangular & 0.7 & 5.6 & 4 & Stewart and others, $1997^{34}$ \\
\hline
\end{tabular}

iables had reached convergence (defined as a percentage change in the output mean, standard deviation, and percentiles of less than $1.5 \%$ after each 100 iterations). Summary statistics presented for the model outputs were the mean and range within which $90 \%$ of the cost-effectiveness estimates fell, termed the "cost-effectiveness range." The evaluation of CERs rests on a comparison with the cost-effectiveness of alternative uses of resources, which will depend on the 
TABLE 3

Expected incremental cost per primigravidae (1995 US\$)*

\begin{tabular}{|c|c|c|c|}
\hline \multirow[b]{2}{*}{ Drug regimen } & \multicolumn{3}{|c|}{ Economic strata } \\
\hline & Very low income & Middle income & Higher income \\
\hline \multicolumn{4}{|l|}{ Chloroquine } \\
\hline Drugs & $\$ 0.50(38 \%)$ & $\$ 0.50(35 \%)$ & $\$ 0.50(21 \%)$ \\
\hline Staff & $\$ 0.36(28 \%)$ & $\$ 0.48(34 \%)$ & $\$ 1.38(59 \%)$ \\
\hline Health education and training & $\$ 0.44(34 \%)$ & $\$ 0.44(31 \%)$ & $\$ 0.44(19 \%)$ \\
\hline Mean incremental cost & $\$ 1.30(100 \%)$ & $\$ 1.42(100 \%)$ & $\$ 2.31(100 \%)$ \\
\hline \multicolumn{4}{|c|}{ Sulfadoxine-pyrimethamime ( 2 doses, primigravidae only) } \\
\hline Drugs & $\$ 0.32(29 \%)$ & $\$ 0.32(26 \%)$ & $\$ 0.32(15 \%)$ \\
\hline Staff & $\$ 0.36(32 \%)$ & $\$ 0.48(38 \%)$ & $\$ 1.38(64 \%)$ \\
\hline Health education and training & $\$ 0.44(39 \%)$ & $\$ 0.44(36 \%)$ & $\$ 0.44(21 \%)$ \\
\hline Mean incremental cost & $\$ 1.13(100 \%)$ & $\$ 1.25(100 \%)$ & $\$ 2.14(100 \%)$ \\
\hline
\end{tabular}

* Percentage of mean incremental cost in parentheses.

specific context. However, based on rough guidelines for countries with per capita GNP below US\$765, the intervention was classified as an "attractive" use of resources if the CER range fell entirely below US $\$ 150.45$

Intervention specifications. For SP intermittent treatment, the robustness of the cost-effectiveness conclusions was tested by considering 2 further treatment scenarios. First, the 2dose SP regimen was extended to include all gravidae, to capture probable actual practice. The Cochrane review did not report a significant impact on birth weight for multigravidae, so the increase in birth weight $i$ was set at zero for multigravidae by multiplying the effective reduction in NNMR, $D$, by the proportion of antenatal attendees who are primigravidae. The cost per woman was reduced to reflect the allocation of the fixed costs of supervision, training, and health education over more women per facility (total costs would of course rise). Second, a 3-dose SP regimen was considered also to be given to all gravidae, as a possible response to increasing human immunodeficiency virus (HIV) prevalence. With this specification, costs were raised to include the additional dose of SP and an extra clinic visit. To capture lower patient compliance with the 3-dose regimen, $g$ was reduced, and the effective reduction in NNMR $D$ was multiplied by a parameter $v_{3}$, the probability of returning for a third clinic visit. The other effectiveness assumptions and the probability distribution of unprotected birth weights were not altered from the 2-dose all-gravidae scenario.

Total cost. To assess affordability, the total cost of full coverage was estimated as a percentage of the existing public-sector health budget for a typical very-low-income country (based on Tanzanian population and health-sector budget data $^{46,47}$ ).

\section{RESULTS}

At complete drug sensitivity $(r=0)$, the DYLLs averted per primigravida with the CQ regimen were on average 0.09 for very-low-income and middle-income countries and 0.10 for higher-income countries. With the 2-dose SP regimen for primigravidae, 0.14 DYLLs were averted per primigravida for very-low-income and middle-income countries and 0.16 for higher-income countries. More DYLLs were averted per woman in higher-income countries because a life table with a higher life expectancy at birth was used, meaning that more YLLs were saved per death averted. Sulfadoxine-pyrimethamine was more effective than CQ even when there was no resistance to either drug, because compliance was assumed to be lower with CQ than with SP.

The mean incremental costs per pregnancy for these CQ and SP regimens are shown in Table 3. The incremental cost with SP was $\$ 1.13$ in very-low-income countries, $\$ 1.25$ in middle-income countries, and $\$ 2.14$ in higher-income countries, the increase in costs in higher income countries being explained by higher salaries. In very-low-income and middle-income countries, drugs and staff each accounted for approximately one-third of the incremental cost, with health education and training making up the remaining third. In higher-income countries, salary costs made up about twothirds of the incremental cost, with drugs falling to only $15 \%$. All costs were higher with the CQ regimen because of the higher drug cost per pregnancy. The mean incremental cost with CQ was $\$ 1.30$ in very-low-income countries, $\$ 1.42$ in middle-income countries, and $\$ 2.31$ in higher-income countries. Although the average drug cost per dose was higher with SP than with CQ, the CQ regimen demanded an average of 16 doses per pregnancy, giving a higher total drug cost per pregnancy (mean of $\$ 0.50$ compared with $\$ 0.32$ for SP). Drugs therefore were the most important element of incremental costs with CQ for very-low-income and middleincome countries, although salaries remained the most important for higher-income countries.

The cost-effectiveness ranges for SP and CQ at complete drug sensitivity $(r=0)$ for the 3 economic strata are shown in Figure 2. In very-low-income countries, the range was \$4-\$27 for SP and \$7-\$49 for CQ. CQ was slightly less cost-effective than SP, because of both higher costs per primigravida and lower DYLLs averted.

The cost-effectiveness ranges for middle-income countries were little different from those for very-low-income countries. However, the ranges were significantly higher in countries in the higher-income stratum, as the impact of increased costs due to higher salaries outweighed the increased DYLLs averted due to the higher-life expectancy. For all income levels, the cost-effectiveness ranges for both SP and CQ fell clearly below $\$ 150$ per DYLL averted, meaning that with no resistance, either regimen would be considered an "attractive" option for all economic strata.

The above results were all based on full drug sensitivity. 


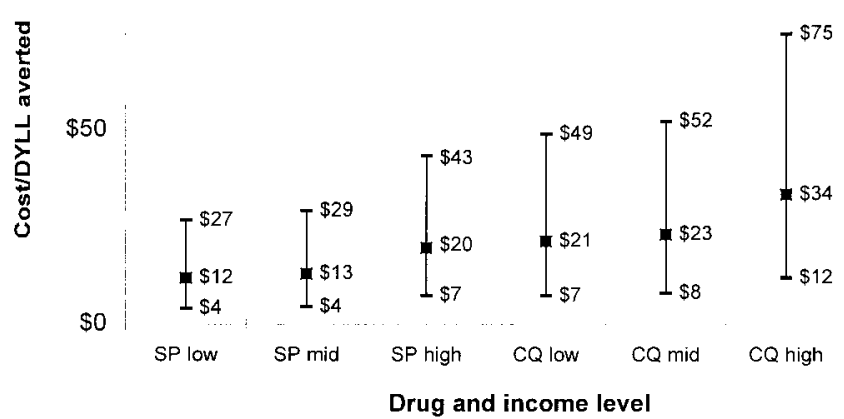

FIGURE 2. Cost per discounted year of life lost (DYLL) averted by chloroquine prophylaxis (CQ) and 2-dose sulfadoxine-pyrimethamine (SP) intermittent treatment for primigravidae: mean ( $\square$ ) and cost-effectiveness range in very-low-income (low), middle-income (mid), and higher-income (high) countries with no drug resistance (1995 US\$).

Allowing for drug resistance reduced effectiveness and caused the CER to increase. The relationship between the cost-effectiveness range and the level of RII/RIII resistance for very-low-income countries is shown for CQ and SP in Figure 3 . The arrows show the rate of RII/RIII resistance above which the cost-effectiveness range is no longer entirely lower than $\$ 150$. The cost-effectiveness range for the CQ regimen remained lower than $\$ 150$ up to $67 \%$ resistance, and the SP regimen up to $82 \%$ (note that resistance thresholds reported here differ slightly from those included in the publication on the full study in the Lancet, ${ }^{16}$ because a new simulation of the model was run to explore the impact of variations in the intervention specification).

The cost-effectiveness implications of the model variations are shown in Figure 4, which compares the relationship between the upper limit of the cost-effectiveness range and the level of RII/RIII resistance for very-low-income countries for 3 specifications of the SP regimen: 2 doses per pregnancy for primigravidae only, 2 doses for all gravidae, and 3 doses for all gravidae (assuming zero benefits for multigravidae). If a 2-dose regimen were provided to all gravidae, the cost-effectiveness range at zero resistance would be $\$ 12-\$ 70$, and the level of RII/RIII resistance up to which the cost-effectiveness range remained lower than $\$ 150$ would fall to $54 \%$. Providing 3 doses to all gravidae further increased the cost-effectiveness range at zero resistance to $\$ 22-\$ 129$, reducing the $\$ 150$ threshold to $14 \%$ resistance.

The expected total cost to government of full coverage with each regimen is shown in Table 4. The CQ regimen in a typical very-low-income country represented $0.19 \%$ of the existing government health care budget, the 2-dose SP regimen for primigravidae $0.17 \%$, the 2-dose regimen for all gravidae $0.97 \%$, and the 3 -dose regimen for all gravidae $1.19 \%$.

\section{DISCUSSION}

The model provides a framework to investigate the operational cost-effectiveness of alternative malaria prevention strategies in pregnancy and allows the impact of variations in drug resistance, intervention specification, and socioeco-
Chloroquine

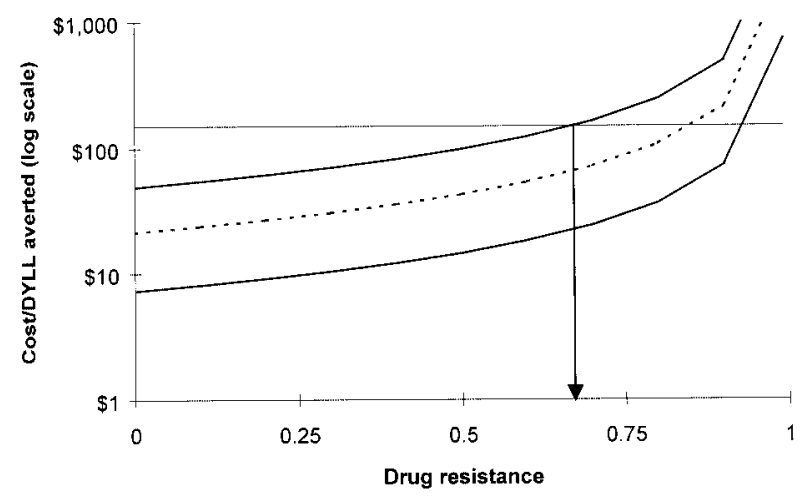

Sulfadoxine-Pyrimethamine

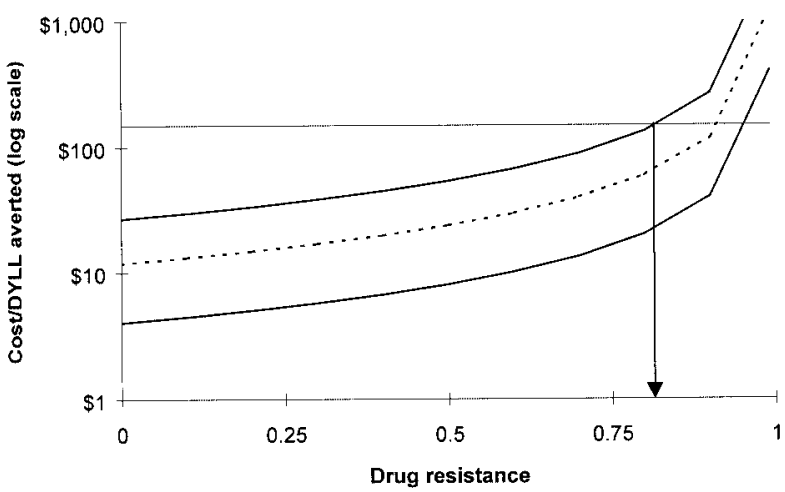

FIGURE 3 (top). Mean and cost-effectiveness range for chloroquine chemoprophylaxis for primigravidae as a function of RII/RIII drug resistance, for very-low-income countries (1995 US\$). DYLL $=$ discounted year of life lost. Figure 3 (bottom). Mean and costeffectiveness range for sulfadoxine-pyrimethamine intermittent treatment for primigravidae as a function of RII/RIII drug resistance, for very-low-income countries (1995 US\$).

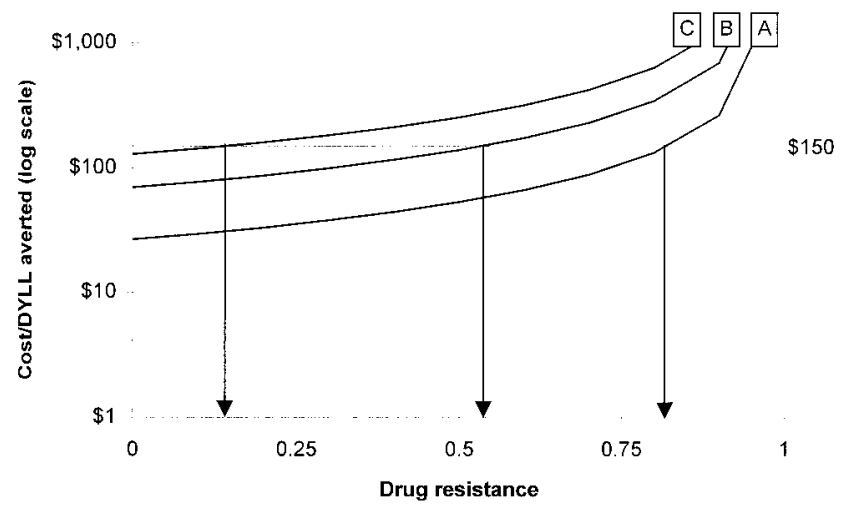

FIGURE 4. Upper limit of the cost-effectiveness range for sulfadoxine-pyrimethamine intermittent treatment in a very-low-income country with (A) 2 doses for primigravidae only, (B) 2 doses for all gravidae, and (C) 3 doses for all gravidae (1995 US\$). DYLL = discounted year of life lost. 
TABLE 4

Estimated annual mean incremental cost for Tanzania* (very-lowincome country) of chloroquine (CQ) and sulfadoxine-pyrimethamine (SP) antenatal regimens (1995 US\$)

\begin{tabular}{llcc}
\hline Drug & \multicolumn{1}{c}{ Regimen } & $\begin{array}{c}\text { Government } \\
\text { cost per } \\
\text { annum }\end{array}$ & $\begin{array}{c}\text { Cost as } \\
\text { percentage of } \\
\text { government } \\
\text { health budget }\end{array}$ \\
\hline CQ & Weekly doses & $\$ 179,349$ & $0.19 \%$ \\
SP & $\begin{array}{c}\text { 2-dose regimen, primigravi- } \\
\text { dae only }\end{array}$ & $\$ 155,896$ & $0.17 \%$ \\
& $\begin{array}{c}\text { 2-dose regimen, all pregnant } \\
\text { women } \\
\text { 3-dose regimen, all pregnant } \\
\text { women }\end{array}$ & $\$ 1,119,080$ & $1.19 \%$ \\
& & \\
\hline
\end{tabular}

* Based on the following estimates for Tanzania: population of 29.2 million $;{ }^{47}$ crude birth rate of 42.6 per 1,$000 ; 7^{71} 17 \%$ of all births born to primigravidae; $93.2 \%$ of primigravidae and $91.8 \%$ of all pregnant women receive antenatal care ${ }^{34} 70 \%$ of population at high risk of malaria; government health budget per annum of $\$ 94$ million (including donor contributions); ${ }^{46}$ no cost recovery.

nomic setting to be explored. The results demonstrate the relative cost-effectiveness of SP intermittent treatment compared with CQ prophylaxis, even with zero resistance to both drugs. The relative attractiveness of the $\mathrm{SP}$ regimen is driven by the assumed higher compliance and lower costs per woman. Even with SP RII/RIII resistance levels of over $40 \%$, the $\mathrm{SP}$ regimen would on average still be more cost-effective than the $C Q$ regimen with zero $C Q$ resistance. Because current levels of resistance to $\mathrm{CQ}$ in sub-Saharan Africa are much higher than those for $\mathrm{SP}^{33}$ in practice the difference in cost-effectiveness between the 2 drug regimens would be accentuated. However, in addition to the costs and effects included in the model, the choice between the regimens will be affected by other concerns, such as the attitude of policy makers to the risk of SP side effects and the potential impact of widespread SP use on the growth rate of SP resistance. The importance of compliance in influencing the effectiveness of a regimen highlights the need to investigate interventions to improve adherence to $\mathrm{CQ}$ chemoprophylaxis through, for example, the use of coated tablets, prepackaging of drugs, or intensified health education, ${ }^{12}$ and to evaluate the effectiveness of intermittent treatment regimens with $\mathrm{CQ}$.

This analysis formed part of a larger study to investigate the cost-effectiveness of a range of interventions to prevent malaria and to improve its treatment in sub-Saharan Africa. ${ }^{16}$ The use of a consistent modeling framework allows the costeffectiveness of the different interventions to be compared. For example, in a very-low-income country, the cost-effectiveness range for insecticide treated nets (ITNs) for children under $5 \mathrm{yr}$ was $\$ 19-85$ per DALY averted where nets are distributed as part of the program, and \$4-10 where there is already a high degree of net ownership and only insecticide treatment is provided. For residual spraying, the cost-effectiveness range was \$16-29 per DALY averted with 1 spraying round per year, and \$32-58 with 2 rounds. Even though the analysis presented here considers only the mortality component of the DALY, making the effectiveness estimates conservative, the results are of comparable cost-effectiveness with these other malaria prevention methods. Because of the considerable overlap in the cost-effectiveness ranges, no single intervention emerges as clearly the most cost-effective. However, up to SP RII/RIII resistance levels of $65 \%$, the 2-dose SP regimen for primigravidae would be at least as cost-effective as ITNs for children under $5 \mathrm{yr}$ (including the provision of nets). Chloroquine prophylaxis would be at least as cost-effective as ITNs up to $40 \%$ CQ resistance.

Rough cost-effectiveness guidelines for low-income countries classified interventions as an "attractive" use of resources if the cost per DALY averted was below $\$ 150 .{ }^{45}$ The results show that in the absence of drug resistance, the interventions are clearly a good use of resources. For both $\mathrm{CQ}$ and the 2-dose SP regimen for primigravidae, the cost-effectiveness ranges fell below the $\$ 150$ threshold for all economic strata. Even when resistance is allowed for, both drug regimens remained cost-effective up to high levels of parasitological resistance. The interventions were not only highly cost-effective but also relatively affordable to developing countries, absorbing well under $1.5 \%$ of the current healthsector budget.

The interventions appeared highly cost-effective despite the relatively narrow definition of health benefits included. The model incorporated only reduced mortality in the neonatal period, excluding increased survival for children older than $28 \mathrm{~d}$ and potential benefits from reductions in morbidity and mortality for mothers. Chemoprophylaxis or intermittent treatment in primigravidae is associated with a significant reduction in the number of malaria episodes treated for the mother relative to unprotected primigravidae. ${ }^{9}$ Although this morbidity reduction in mothers would be unlikely to have a significant effect on the DALYs averted (because of the low disability weighting and short duration of a malaria episode), it could lead to significant cost savings for households and providers because of the reduction in treatment seeking. More significantly, the impact on maternal anemia was not incorporated. Malaria infection is strongly associated with moderate and severe anemia in primigravidae, which in turn is associated with increased maternal morbidity and mortality. ${ }^{4}$ In fact, the earliest trials of antenatal prophylaxis were prompted primarily by the need to reduce maternal mortality due to severe anemia. ${ }^{48}$ Any impact on maternal mortality could have spin-off effects on the health and well-being of the whole household. ${ }^{49}$ In Kenya, intermittent SP treatment reduced the prevalence of severe anemia (hemoglobin less than $8 \mathrm{~g} / \mathrm{dL}$ ) among primigravidae to $14.5 \%$, compared with $23.7 \%$ in the control group. ${ }^{32}$ The impact of severe anemia on maternal mortality is not known, but assuming, for example, that severe anemia doubled the risk of maternal mortality, and that the baseline maternal mortality rate was 450 per 100,000 , SP intermittent treatment would avert 0.0002 deaths per primigravida, after adjusting for noncompliance. Converting to DYLLs using an average age at death of 19 $\mathrm{yr}$ and a life expectancy of $52 \mathrm{yr}$, this would be equivalent to 0.005 DYLLs averted per primigravida, increasing the total DYLLs averted per primigravida by the intervention by around $5 \%$.

A number of caveats should be borne in mind in interpreting these promising cost-effectiveness results. First, the modeled impact on child survival has not been empirically demonstrated; second, varying the specification of the SP regimen reduced its estimated cost-effectiveness; and third, the analysis was based on the assumption that ANC services were already in place. These caveats are explored below.

Although the impact of prophylaxis and intermittent treatment on birth weight in primigravidae has been clearly 
shown, the sample sizes of the studies included in the metaanalysis were too small to demonstrate a significant impact on neonatal mortality even among primigravidae. ${ }^{9}$ It was therefore necessary to model the impact on mortality based on empirical evidence of birth weight distributions and birth weight-specific NNMRs. However, the available data on birth weights and mortality are limited and are unlikely to be representative of the whole of sub-Saharan Africa. One might expect birth weights to be positively correlated with economic development, and birth weight-specific mortality rates negatively correlated. Because the data on birth weights in unprotected primigravidae and birth weight-specific mortality all came from studies conducted in middle-income and very-low-income countries, it is possible that the model overestimates effectiveness in higher-income countries.

In modeling the reduction in the NNMR following an increase in birth weight, no distinction was made between preterm delivery and intrauterine growth retardation as causes of low birth weight. The NNMR at a given birth weight is higher for a preterm baby than for a full-term baby with retarded growth. ${ }^{50}$ Although there is evidence that malaria affects both gestational age and weight for age, ${ }^{50}$ no studies have demonstrated that prophylaxis or intermittent treatment reduces the prevalence of preterm births. ${ }^{9}$ It is possible that the intervention could have a differential impact, with, for example, a bigger impact on the birth weight for gestational age than on the gestational age at delivery, and may therefore not have the impact on neonatal mortality predicted by the model. The effectiveness of the interventions may therefore be overestimated.

Although the Cochrane review did not report a significant effect of prophylaxis on LBW in multigravidae, in practice it may be inappropriate or impractical to restrict the intervention to primigravidae. For example, it may be logistically complex to provide different services to different groups and politically problematic to exclude some women from what is perceived to be a valuable service. Altering the specification of the SP regimen to include all gravidae, rather than primigravidae only, had a significant impact on the cost-effectiveness results. The SP RII/RIII resistance level up to which the cost-effectiveness range remained below the $\$ 150$ threshold was reduced from $82 \%$ to $54 \%$. However, these estimations assumed zero effectiveness for all multigravidae, which is likely to be a very conservative assumption. For example, in Malawi the proportion of LBW babies born to women without placental malaria was significantly lower than the proportion born to women with placental malaria for women both in their second pregnancy and in their third or greater pregnancy. ${ }^{50}$ There is some evidence that the risk of infection increases in grandemultigravidae, ${ }^{20}$ and in low-transmission areas where acquired immunity is low, all pregnant women may be at risk. It is also possible that protecting a woman during her first pregnancy could lead to enhanced susceptibility to malaria during her second pregnancy, ${ }^{51}$ although no evidence was found of increased risk in second pregnancies in a study of Gambian women who had received prophylaxis as primigravidae. ${ }^{8}$

Human immunodeficiency virus infection has been found to lead to a significant increase in malaria prevalence in pregnant women of all parities, ${ }^{52}$ and malaria in- fections in pregnancy may increase the risk of mother-tochild HIV transmission. ${ }^{53}$ Targeting all pregnant women in areas of high HIV seroprevalence may, therefore, be justified. Moreover, it has been argued that 2 doses of SP per pregnancy may be inadequate for HIV-positive women and that more frequent doses would be preferable. ${ }^{36,52}$ Rates of HIV infection in sub-Saharan Africa are increasing fast, with a median HIV prevalence among antenatal women in sub-Saharan Africa of 5\% in rural areas and 6\% in urban areas, and rates as high as $47 \%$ have been reported in rural areas of Zimbabwe. ${ }^{54}$ Because of the costs and difficulties involved in screening all pregnant women for HIV, it may be necessary to administer the additional doses to all women in areas with high rates of HIV prevalence. The results showed that providing $3 \mathrm{SP}$ doses to all gravidae (assuming zero effects for multigravidae) further reduced the resistance threshold up to which the costeffectiveness range remained below $\$ 150$ to $14 \%$. Again, it is possible that this is a conservative estimate, because first, there may be positive benefits to multigravidae, and second, HIV infection, by diminishing the capacity of pregnant women to control malaria infection, ${ }^{55}$ may increase the prevalence of LBW and potentially the effectiveness of the intervention. On the other hand, it has been argued that monthly SP doses might be required in populations with high rates of seropositivity, ${ }^{52}$ increasing the costs of the intervention still further.

The cost analysis was based on the assumptions that ANC services were already in place and that the new intervention could be added to this existing infrastructure. Although in most of sub-Saharan Africa the percentage of primigravidae receiving ANC is high (median of $89 \%$ for 17 countries $^{34}$ ), there are some exceptions. For instance, in Burkina Faso only $61 \%$ of primigravidae attended ANC, and in Niger only $32 \%$. The incremental costs to both the facility and to women would be much greater than estimated here if it were necessary to set up an entirely new ANC service, and these costs would depend on many factors, including local unit costs, the package of ANC offered, and the existing infrastructure of health facilities. This variation is demonstrated by ANC costing studies, which provide cost estimates per visit ranging from $\$ 0.05-\$ 0.15$ in Tanzanian government dispensaries, ${ }^{56}$ to $\$ 0.75$ in the Gambia, ${ }^{57}$ and to $\$ 8.41$ and $\$ 12.53$ in South Africa ${ }^{58,59}$ (1995 US\$).

It is possible that if wide coverage of ANC services were not attainable, community-based health workers such as traditional birth attendants or village health workers (VHWs) could deliver the intervention. Traditional birth attendants were found to be an effective and appropriate channel for providing antimalarial and iron prophylaxis to pregnant women in the Gambia, even though they received no additional payment. ${ }^{20,60}$ However, a well-supported VHW program in Kenya was able to achieve only $29 \%$ coverage of primigravidae, ${ }^{61}$ leading the authors to conclude that the program was not effective in providing prophylaxis and that asking VHWs to distribute the drugs may have overloaded them.

In summary, assuming the hypothesized link between an increase in birth weight and reduction in NNMR holds, CQ prophylaxis and SP intermittent treatment for primi- 
gravidae are cost-effective interventions compared to other methods of malaria control and to interventions for other health problems. This remains the case up to high levels of parasitological resistance to either drug. In addition to being cost-effective, the interventions are also relatively affordable for sub-Saharan African governments. The analysis lends weight to the argument that there should be a drive to extend coverage of preventive strategies in pregnancy to all women in malarious areas of Africa. It also shows that modifying the intervention in response to increasing HIV prevalence could substantially reduce its cost-effectiveness, although the impact of HIV on the burden of disease, the effectiveness of the interventions, and the costs of any intervention modifications required needs further exploration. Finally, because resistance to SP is expected to grow rapidly as it is more widely used in subSaharan Africa, research is urgently needed to identify potential replacement drugs to enable the provision of effective antenatal malaria prevention in the future.

Acknowledgments: This project has been undertaken in collaboration with the Malaria Programme of the London School of Hygiene and Tropical Medicine and with the Malaria Consortium of the London School of Hygiene and Tropical Medicine and the Liverpool School of Tropical Medicine. We are grateful for comments on earlier drafts from David Evans, Paul Garner, Brian Greenwood, Rüdiger Pittrof, and Caroline Shulman. We would also like to thank the many other researchers and control staff who provided technical advice.

Financial support: This investigation received financial support from the Global Forum for Health Research, using a grant provided by the World Bank. Anne J. Mills and Catherine A. Goodman are members of the London School of Hygiene and Tropical Medicine Health Economics and Financing Programme, which is supported by the United Kingdom Department for International Development. Catherine A. Goodman is supported by a Research Training Fellowship from the Wellcome Trust (ref 060184).

Authors' addresses: Catherine A. Goodman and Anne J. Mills, Health Policy Unit, London School of Hygiene and Tropical Medicine, Keppel Street, London WC1E 7HT, United Kingdom. Paul G. Coleman, Centre for Tropical Veterinary Medicine, The University of Edinburgh, Easter Bush Veterinary Centre, Roslin, Midlothian, Scotland EH25 9RG, United Kingdom.

Reprint requests: Catherine Goodman, Health Policy Unit, London School of Hygiene and Tropical Medicine, Keppel Street, London WC1E 7HT, United Kingdom, Telephone: 44 (0)20 7927 2104, Fax: 44 (0)20 76375391 (e-mail catherine.goodman@1shtm.ac.uk).

\section{REFERENCES}

1. WHO, 1993. Implementation of the global malaria control strategy-Report of a WHO study group on the implementation of the global plan of action for malaria control 1993-2000. Geneva, Switzerland: World Health Organization. WHO Technical Report Series 839.

2. Phillips-Howard PA, 1999. Epidemiological and control issues related to malaria in pregnancy. Ann Trop Med Parasitol 93: S11-S17.

3. Steketee RW, Wirima JJ, Campbell CC, 1996. Developing effective strategies for malaria prevention programs for pregnant African women. Am J Trop Med Hyg 55: 95-100.

4. Shulman CE, Graham WJ, Jilo H, Lowe BS, New L, Obiero J, Snow RW, Marsh K, 1996. Malaria is an important cause of anaemia in primigravidae: evidence from a district hospital in coastal Kenya. Trans $R$ Soc Trop Med Hyg 90: 535-539.

5. Brabin BJ, 1983. An analysis of malaria in pregnancy in Africa. Bull World Health Organ 61: 1005-1016.
6. McGregor IA, 1984. Epidemiology, malaria and pregnancy. Am J Trop Med Hyg 33: 517-525.

7. McCormick MC, 1985. The contribution of low birth weight to infant mortality and childhood morbidity. $N$ Engl J Med 312: 82-90.

8. Greenwood AM, Menendez C, Alonso PL, Jaffar S, Langerock P, Lulat S, Todd J, B MB, Francis N, Greenwood BM, 1994. Can malaria chemoprophylaxis be restricted to first pregnancies? Trans $R$ Soc Trop Med Hyg 88: 681-682.

9. Gülmezoglu AM, Garner P, 1998. Malaria in pregnancy in endemic areas (Cochrane Review). In: The Cochrane Library, Issue 3. Oxford, UK: Update Software.

10. Government of Kenya, Ministry of Health, 1997. National Guidelines for Diagnosis, Treatment and Prevention of Malaria for Health Workers. Nairobi, Kenya: Government of Kenya, Ministry of Health.

11. Heymann DL, Steketee RW, Wirima JJ, McFarland DA, Khoromana CO, Campbell CC, 1990. Antenatal chloroquine chemoprophylaxis in Malawi: chloroquine resistance, compliance, protective efficacy and cost. Trans $\mathrm{R}$ Soc Trop Med Hyg 84: 496-498.

12. Helitzer-Allen DL, McFarland DA, Wirima JJ, Macheso AP, 1993. Malaria chemoprophylaxis compliance in pregnant women: a cost-effectiveness analysis of alternative interventions. Soc Sci Med 36: 403-407.

13. Schultz LJ, Steketee RW, Chitsulo L, Wirima JJ, 1995. Antimalarials during pregnancy: a cost-effectiveness analysis. Bull World Health Organ 73: 207-214.

14. Schultz LJ, Steketee RW, Chitsulo L, Macheso A, Kazembe P, Wirima JJ, 1996. Evaluation of maternal practices, efficacy, and cost-effectiveness of alternative antimalarial regimens for use in pregnancy: chloroquine and sulfadoxine-pyrimethamine. Am J Trop Med Hyg 55: 87-94.

15. Goodman CA, Mills AJ, 1999. Review article: the evidence base on the cost-effectiveness of malaria control measures in Africa. Health Policy Plann 14: 301-312.

16. Goodman CA, Coleman PG, Mills AJ, 1999. Cost-effectiveness of malaria control in sub-Saharan Africa. Lancet 354: 378 385 .

17. Goodman C, Coleman P, Mills A, 2000. Economic Analysis of Malaria Control in Sub-Saharan Africa. Geneva, Switzerland: Global Forum for Health Research.

18. Murray CJL, Lopez AD, 1996. The Global Burden of Disease: A Comprehensive Assessment of Mortality and Disability From Diseases, Injuries and Risk Factors in 1990 and Projected to 2020. Cambridge, MA: Harvard School of Public Health (on behalf of WHO and the World Bank), distributed by Harvard University Press.

19. Wilcox AJ, Russell IT, 1983. Birthweight and perinatal mortality. I: On the frequency distribution of birthweight. Int J Epidemiol 12: 314-318.

20. Greenwood BM, Greenwood AM, Snow RW, Byass P, Bennett S, Hatib-N'Jie AB, 1989. The effects of malaria chemoprophylaxis given by traditional birth attendants on the course and outcome of pregnancy. Trans R Soc Trop Med Hyg 83: 589-594.

21. Menendez C, Todd J, Alonso PL, Lulat S, Francis N, Greenwood BM, 1994. Malaria chemoprophylaxis, infection of the placenta and birth weight in Gambian primigravidae. $J$ Trop Med Hyg 97: 244-248.

22. Cot M, Le Hesran JY, Miailhes P, Esveld M, Etya'ale D, Breart $\mathrm{G}, 1995$. Increase of birth weight following chloroquine chemoprophylaxis during the first pregnancy: results of a randomized trial in Cameroon. Am J Trop Med Hyg 53: 581585.

23. Fleming AF, Ghatoura GB, Harrison KA, Briggs ND, Dunn DT, 1986. The prevention of anaemia in pregnancy in primigravidae in the Guinea savanna of Nigeria. Ann Trop Med Parasitol 80: 211-233.

24. Ashworth A, Feachem RG, 1985. Interventions for the control of diarrhoeal diseases among young children: prevention of low birth weight. Bull World Health Organ 63: 165-184.

25. Greenwood AM, Armstrong JR, Byass P, Snow RW, Greenwood 
BM, 1992. Malaria chemoprophylaxis, birth weight and child survival. Trans $R$ Soc Trop Med Hyg 86: 483-485.

26. McDermott JM, Wirima JJ, Steketee RW, Breman JG, Heymann DL, 1996. The effect of placental malaria infection on perinatal-mortality in rural Malawi. Am J Trop Med Hyg 55: 6165.

27. Wilcox AJ, Russell IT, 1983. Birthweight and perinatal mortality. II: On weight-specific mortality. Int J Epidemiol 12: 319 325 .

28. Wilcox AJ, Russell IT, 1986. Birthweight and perinatal mortality. III: Towards a new method of analysis. Int J Epidemiol 15: $188-196$.

29. Williams BG, Dye C, 1994. Maximum-likelihood for parasitologists. Parasitol Today 10: 489-493.

30. Greenwood AM, Menendez C, Todd J, Greenwood BM, 1994. The distribution of birth weights in Gambian women who received malaria chemoprophylaxis during their first pregnancy and in control women. Trans $R$ Soc Trop Med Hyg 88 . 311-312.

31. Schultz LJ, Steketee RW, Macheso A, Kazembe P, Chitsulo L, Wirima JJ, 1994. The efficacy of antimalarial regimens containing sulfadoxine-pyrimethamine and/or chloroquine in preventing peripheral and placental Plasmodium falciparum infection among pregnant women in Malawi. Am J Trop Med Hyg 51: 515-522.

32. Shulman CE, Dorman EK, Cutts F, Kawuondo JN, Bulmer JN, Peshu N, Marsh K, 1999. Intermittent sulfadoxine-pyrimethamine to prevent severe anaemia secondary to malaria in pregnancy: a randomised placebo-controlled trial. Lancet 353: 632-636.

33. WHO, 1994. Antimalarial Drug Policies: Data Requirements, Treatment of Uncomplicated Malaria and Management of Malaria in Pregnancy. Geneva, Switzerland: World Health Organization, Division of Control of Tropical Diseases. WHO/MAL/94.1070.

34. Stewart MK, Stanton CK, Ahmed O, 1997. Maternal Health Care. Calverton, MD: Macro International. DHS Comparative Studies No. 25.

35. Miller KD, Lobel HO, Satriale RF, Kuritsky JN, Stern R, Campbell CC, 1986. Severe cutaneous reactions among American travelers using pyrimethamine-sulfadoxine (Fansidar) for malaria prophylaxis. Am J Trop Med Hyg 35: 451-458.

36. Parise ME, Ayisi JG, Nahlen BL, Schultz LJ, Roberts JM, Misore A, Muga R, Oloo AJ, Steketee RW, 1998. Efficacy of sulfadoxine-pyrimethamine for prevention of placental malaria in an area of Kenya with a high prevalence of malaria and human immunodeficiency virus infection. Am J Trop Med Hyg 59: 813-822.

37. Verhoeff FH, Brabin BJ, Chimsuku L, Kazembe P, Russell WB, Broadhead RL, 1998. An evaluation of the effects of intermittent sulfadoxine-pyrimethamine treatment in pregnancy on parasite clearance and risk of low birthweight in rural Malawi. Ann Trop Med Parasitol 92: 141-150.

38. United Nations, 1982. Model Life Tables for Developing Countries. New York: United Nations.

39. Phillips M, Mills A, Dye C, 1993. Guidelines for Cost-Effectiveness Analysis of Vector Control. Geneva, Switzerland: World Health Organization. PEEM Guidelines Series 3.

40. Tinker A, Koblinsky MA, 1992. Making Motherhood Safe, World Bank Discussion Paper. Washington DC: World Bank.

41. IMF, 1996. International Financial Statistics Yearbook. Washington DC: International Monetary Fund.

42. IMF, 1997. International Financial Statistics, May. Washington, DC: International Monetary Fund.

43. Palisade, 1997. @Risk. Risk Analysis and Simulation Software Add-In for Microsoft Excel or Lotus 1-2-3. Windows Version. Newfield, NY: Palisade Corporation.

44. Doubilet P, Begg CB, Weinstein MC, Braun P, McNeil BJ, 1985. Probabilistic sensitivity analysis using Monte Carlo simulation. A practical approach. Med Decis Making 5: 157-177.

45. WHO, 1996. Investing in Health Research and Development: Report of the Ad Hoc Committee on Health Research Relating to Future Intervention Options. Geneva, Switzerland: World Health Organization. TDR/Gen/96.1.
46. World Bank, 1994. Tanzania-Role of Government: Public Expenditure Review, Volume 1. Washington, DC: World Bank.

47. World Bank, 1997. World Development Report 1997. The State in a Changing World. New York: Oxford University Press.

48. Fleming AF, 1999. Cost-effectiveness of malaria control in subSaharan Africa [letter]. Lancet 354: 1123.

49. WHO, 1994. Mother-Baby Package: Implementing Safe Moth erhood on Countries. Maternal Health and Safe Motherhood Programme, Division of Family Health.

50. Steketee RW, Wirima JJ, Hightower AW, Slutsker L, Heymann DL, Breman JG, 1996. The effect of malaria and malaria prevention in pregnancy on offspring birth-weight, prematurity, and intrauterine growth-retardation in rural Malawi. Am J Trop Med Hyg 55: 33-41.

51. McGregor IA, 1987. Thoughts on malaria in pregnancy with consideration of some factors which influence remedial strategies. Parassitologia 29: 153-163.

52. Verhoeff FH, Brabin BJ, Hart CA, Chimsuku L, Kazembe P Broadhead RL, 1999. Increased prevalence of malaria in HIVinfected pregnant women and its implications for malaria control. Trop Med Int Health 4: 5-12.

53. Bloland PB, Wirima JJ, Steketee RW, Chilima B, Hightower A Breman JG, 1995. Maternal HIV infection and infant mortality in Malawi: evidence for increased mortality due to placental malaria infection. AIDS 9: 721-726.

54. UNAIDS/WHO, 1998. Report on the Global HIV/AIDS Epidemic. Geneva, Switzerland: UNAIDS

55. Steketee RW, Wirima JJ, Bloland PB, Chilima B, Mermin JH, Chitsulo L, Breman JG, 1996. Impairment of a pregnant woman's acquired ability to limit Plasmodium falciparum by infection with human immunodeficiency virus type-1. Am J Trop Med Hyg 55: 42-49.

56. Gilson L, 1995. Management and health care reform in subSaharan Africa. Soc Sci Med 40: 695-710.

57. Fabricant S, Newbrander W, 1994. The Gambia Health Facilities Cost Study. Boston: Management Sciences for Health.

58. Valli A, Ferrinho PD, Broomberg J, Wilson TD, Robb D, 1991. Costs of primary health care at the Alexandra Health Centre. S Afr Med J 80: 396-399.

59. Broomberg J, Rees H, 1993. Delivering at the right price-the costs of primary maternity care at the Diepkloof Community Health Centre, Soweto. S Afr Med J 83: 272-275.

60. Menendez C, Todd J, Alonso PL, Francis N, Lulat S, Ceesay S, B MB, Greenwood BM, 1994. The effects of iron supplementation during pregnancy, given by traditional birth attendants, on the prevalence of anaemia and provided by community health workers in Saradidi, Kenya. I: Reasons for nonacceptance. Ann Trop Med Parasitol 81: 77-82.

61. Kaseje DC, Sempebwa EK, Spencer HC, 1987. Malaria chemoprophylaxis to pregnant women provided by community health workers in Saradidi, Kenya. I. Reasons for non-acceptance. Ann Trop Med Parasitol 81:77-82.

62. MSH, 1996. International Drug Price Indicator Guide. Boston Management Sciences for Health.

63. WHO, 1995. Model Prescribing Information: Drugs Used in Parasitic Diseases. Geneva, Switzerland: World Health Organization.

64. Foster SD, 1991. Pricing, distribution, and use of antimalarial drugs. Bull World Health Organ 69: 349-363.

65. Picard J, Aikins M, Alonso PL, Armstrong Schellenberg JR, Greenwood BM, Mills A, 1993. A malaria control trial using insecticide-treated bed nets and targeted chemoprophylaxis in a rural area of The Gambia, West Africa. 8: Cost-effectiveness of bed net impregnation alone or combined with chemoprophylaxis in preventing mortality and morbidity from malaria in Gambian children. Trans $R$ Soc Trop Med Hyg 2: 53-57.

66. Ogunbekun I, Adeyi O, Wouters A, Morrow RH, 1996. Costs and financing of improvements in the quality of maternal health services through the Bamako Initiative in Nigeria. Health Policy Plann 11: 369-384.

67. Hanson K, Chindele F, 1992. Costs, Resource Use and Financing: A Study of Monze District, Zambia. New York: UNICEF. Bamako Initiative Technical Report Series.

68. Hanson K, Nkunzimana F, 1992. Les couts et l'utilisation des 
ressources dans les centres de sante de la Province de Muyinga, Burundi. New York: UNICEF. Bamako Initiative Technical Report Series.

69. Steketee RW, Wirima JJ, Slutsker L, Breman JG, Heymann DL,

1996. Comparability of treatment groups and risk-factors for parasitemia at the first antenatal clinic visit in a study of ma- laria treatment and prevention in pregnancy in rural Malawi. Am J Trop Med Hyg 55: 17-23.

70. Mnyika KS, Kabalimu TK, Lugoe WL, 1995. Perception and utilisation of malaria prophylaxis among pregnant women in Dar es Salaam, Tanzania. East Afr Med J 72: 431-435.

71. United Nations Development Program, 1997. Human Development Report. Oxford University Press. 